\title{
El profesor de la Universidad Autónoma de Aguascalientes y las dimensiones de la formación integral
}

María de Lourdes Pacheco González

Buscar el desarrollo integral de la persona y la personalidad es un anhelo, un compromiso, un desideratum, pero también debería obligarnos a todos a cultivar, coadyuvar en esa búsqueda humanista y alcanzar un desarrollo integral.

José Acevedo Acosta

¿Formación integral en profesores?

$\mathrm{E}$ 1 ser humano cuenta con la capacidad para adquirir una serie de recursos que le permitirán dotar de sentido su existencia, de conformarse de la manera más idónea, y una de las vías para lograrlo es la educación, que le permitirá desarrollar su personalidad, sus capacidades e insertarse en el mundo social que le tocó vivir.

A través de la educación, el sujeto, además de adquirir una gama de conocimientos específicos de las diversas ciencias, también desarrollará un sentido crítico, valoral y cívico; es decir, será formado integralmente, entendiendo por formación integral el desarrollo de todas las dimensiones del ser humano.

Las instituciones de educación superior (IES) tienen como objetivo formar a los futuros profesionistas en las diversas áreas del conocimiento existente; sin embargo, tal formación debe ir más allá de la adquisición de conocimiento y desarrollo de habilidades que les permitan desempeñarse laboralmente. Las IES deben formar buenos profesionales, pero también buenos ciudadanos; es decir, debe formarlos íntegramente y para ello, como dice Acevedo et al. (2011: 64): "las universidades [...] deben estar atentas a lo que ocurre en su rededor, sobre todo para apoyar el desarrollo integral de las entidades y regiones donde están inscritas y a la que, en muchos sentidos, se deben".

Ahora bien, ¿quiénes son "las universidades"?, ¿acaso son entes incorpóreos, sin alma? Entonces, ¿quiénes al interior de las universidades han de estar informados del rumbo actual del mundo?, ¿quiénes han de estar conscientes de las necesidades de la comunidad?, ¿quiénes van a contribuir a la formación de futuros profesionistas?

De manera preponderante, el cuerpo docente: profesores que, sin duda alguna, tienen una gran responsabilidad al estar frente a un grupo desde el nivel básico hasta el universitario, puesto que: "El profesorado, además de instruir en ciertos saberes académicos, ha de desarrollar relaciones interpersonales que enriquezcan a todos con nuevos modos de interpretar la realidad; con nuevos valores y actitudes, y con calidad en los comportamientos" (Vázquez y Escámez, 2010: 5).

De ahí que el profesor no debe ser visto únicamente como el facilitador o mediador del proceso enseñanza-aprendizaje, sino también como ese 
$\ll$ Las IES deben formar buenos

profesionales, pero también buenos ciudadanos. 》 sujeto que ayudará al estudiante en su desarrollo integral; sin embargo, este actor también debe dar muestra de poseer una formación integral, ya que de no ser así las IEs no lograrán su cometido y estarán fallando a la sociedad.

\section{Siete dimensiones de la formación integral}

La Universidad Autónoma de Aguascalientes (UAA) en su Modelo Educativo Institucional (MEI), menciona siete dimensiones que el profesor debe ayudar a desarrollar en el estudiante. En esta ocasión, por lo antes mencionado, se abordarán estas dimensiones desde el ser y actuar del profesor.

Dimensión profesional: es indudable que todos aquellos que forman parte de la planta docente de una IES, y en el caso concreto de la UAA, deben demostrar que poseen la formación profesional en el área en la cual se desempeñan, pero también la capacidad pedagógica para la docencia, para así colaborar satisfactoriamente en el proceso enseñanza-aprendizaje que ayudará a que los futuros profesionistas desarrollen las habilidades necesarias para desempeñarse laboralmente y ayudar al progreso óptimo de la sociedad.

Dimensión intelectual: se refiere a la capacidad para generar juicios, criticidad, análisis, entre otros. Todo docente debe dar cuenta de esta capacidad en sus cátedras al tener apertura a escuchar las opiniones de los estudiantes, así como proponer temas alternos a los contenidos del programa de la materia, pero que resulten atractivos o complementarios al currículo. Del mismo modo, como indica el MEI, los profesores han de "[propiciar] el diálogo reflexivo y [desafiar] intelectualmente a los alumnos" (UAA, 2007: 10), con lo cual sacará al estudiantado de un estado de pasividad a un estado de actividad, de búsqueda de conocimiento.

Dimensión actitudinal: este tipo de competencias se enfocan al "saber actuar", donde el trabajo en equipo, la resiliencia, adaptabilidad, entre otras habilidades, son importantes. En el caso del profesorado, esta dimensión se presenta al ser ca- paz de resolver problemas áulicos, ya sea entre estudiantes o entre estudiante y profesor, al trabajar colaborativamente con compañeros de la misma área profesional o diferente para poder sacar proyectos profesionales adelante.

Dimensión valoral: aun cuando su trabajo es enseñar contenidos específicos de una materia, no cabe duda que todo profesor se convierte en educador moral, muchas veces (o casi siempre) inconscientemente, de ahí la importancia de que los profesores tengan claridad en cuanto a sus propios valores a fin de no mostrar incoherencia frente a los estudiantes; por ejemplo, decirse responsable pero nunca revisar ni mucho menos devolver tareas a los estudiantes.

Dimensión física: la UAA, preocupada por la salud física de sus estudiantes, ha contemplado esta dimensión en el MEI; sin embargo, los profesores no pueden ni deben quedar exentos de ésta, de ahí que el cuerpo docente tiene como responsabilidad cuidarse a sí mismo en su salud integral, recordando que para la Organización Mundial de la Salud "la salud es un estado de completo bienestar físico, mental y social, y no solamente la ausencia de afecciones o enfermedades" (oms, 2017). Este bienestar total se verá reflejado en lo laboral, entre otras cosas, al no tener ausentismo en su relación con sus pares o demás miembros de la comunidad universitaria.

Dimensión cultural: por cultura se entiende el "conjunto de modos de vida creados, aprendidos y transmitidos por una generación a otra, entre los miembros de una sociedad particular" (Abbagnano, 1974); estos modos de vida incluyen lengua, religión, expresión artística, modos de trabajo, etc., por lo cual, todo profesor, al ser miembro de una cultura particular, no sólo vivirá acorde a ella, sino que se convertirá en transmisor y generador de la misma.

$\ll$ El profesor no debe ser visto únicamente como el facilitador

o mediador del proceso enseñanza-aprendizaje, sino también como ese sujeto que ayudará al estudiante en su desarrollo integral; por ello, también debe dar muestra de poseer una formación integral. 》 
Dimensión social: el individuo, desde su nacimiento, está inmerso en diversos grupos que le ayudan en su proceso de socialización y adquisición de los variados conocimientos existentes; sin embargo, también "necesita adquirir las ideas y sentimientos que constituyen la conciencia colectiva e interiorizarlos en su propia conciencia. [Y] dicha labor, dado que no se produce espontáneamente, sólo puede ser resultado de una acción deliberada e intencional: la educación" (Di Pietro, 2004: 108).

Así es como la escuela se convierte en el espacio en que pasa la mayor parte de su vida y donde el profesor juega un papel de suma importancia; por tanto, quien ha tomado la decisión de ser profesor vive esta parte primordial de la socialización en su máxima expresión, puesto que en su diaria convivencia con los estudiantes da muestra de lo que es estar con los otros, atenderlos, escucharlos y, sobre todo, ayudarlos a aprender ese estar con los otros.

\section{Conclusión}

La sociedad tiene múltiples necesidades insatisfechas, y seguramente otras están por emerger; está ávida de profesionales "conocedores de la realidad que vive el país y solidarios y comprometidos en la solución de sus necesidades" (Acevedo et al., 2011). Para lograr mayores niveles de satisfacción, se necesitan profesionistas responsables, justos, honestos, puntuales, serviciales, que no piensen solamente en sí mismos y en mantener su estatus; se requiere de profesionales con compromiso ciudadano, gente íntegra, y para ello las IES juegan un papel importante.

Por lo anterior, es de suma importancia que el cuerpo de profesores de las IES no solamente esté capacitado en lo profesional, sino que también lo demuestre en sus valores y actitudes, en un estado de salud óptimo, en relaciones sociales sanas, con un bagaje cultural extenso, así como en la apertura hacia ideas distintas a las propias. A modo de invitación, queda el que como profesores se analice y reflexione individualmente acerca de las dimensiones mencionadas, de tal manera que se determine cómo se está en cada una de ellas, cuál requiere ser fortalecida, cuál está olvidada, recordando que estas dimensiones forman parte de nuestra persona, y que al estar frente a jóvenes universitarios afloran y los educan también.

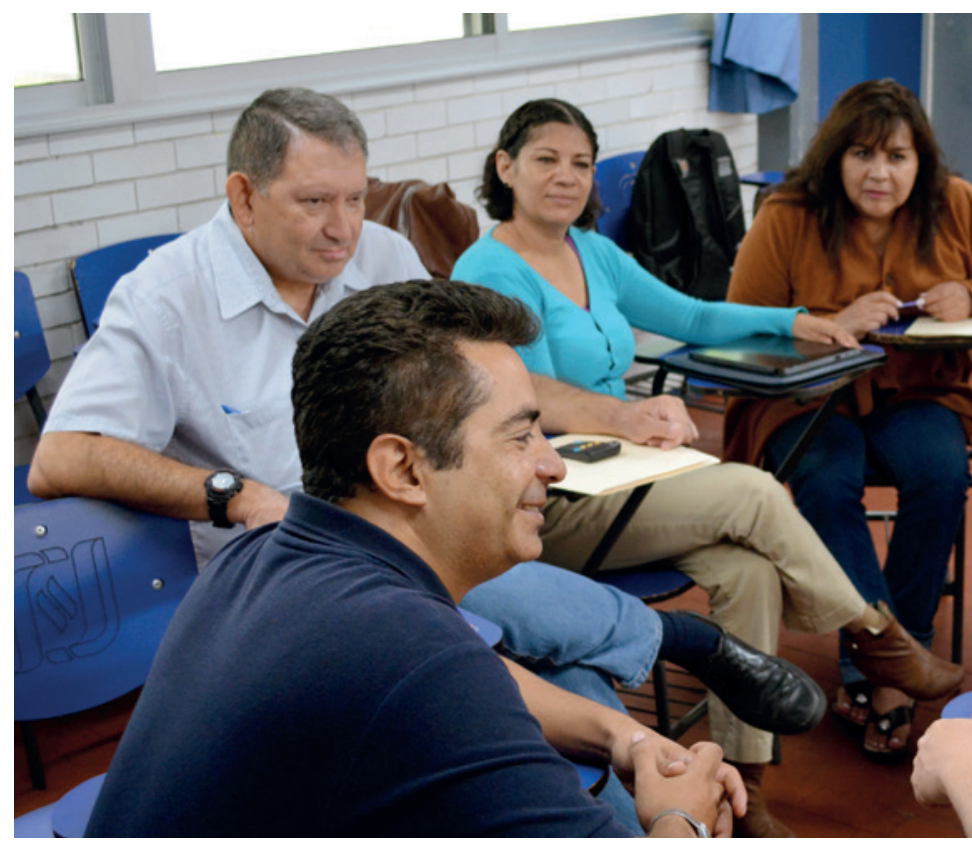

\section{Fuentes de consulta}

Abbagnano, N. (1974). Diccionario de filosofia. México: FCE.

Acevedo, J., Bernal, R., Camacho, S., Chávez, J., Láriz, J. y Quintanar, J. (2011). Ética y humanismo en la educación. México: Universidad Autónoma de Aguascalientes.

Di Pietro, S. (2004). El concepto de socialización y la antinomia individuo/sociedad en Durkheim. Revista Argentina de Sociología, 2(3). Recuperado el 10 de julio de 2017, en: www.redalyc. org/articulo.oa?id=26920306.

Organización Mundial de la Salud. (2017). Acerca de la oms. Quiénes somos y qué hacemos. oms. Consultada el 26 de junio de 2017, en: www.who.int/about/es/.

Universidad Autónoma de Aguascalientes. (2007). Modelo Educativo Institucional, en Correo Universitario, No. 15, séptima época, 29 de mayo de 2015. Primera reimpresión. México: UAA. Recuperado el 7 de junio de 2017, en: http://www.uaa.mx/nu/.

Vázquez, V. y Escámez, J. (2010). La profesión docente y la ética del cuidado. REDIE Revista Electrónica de Investigación Educati$v a,(12), 1-18$. Recuperado el 5 de julio de 2017, en: http://www.redalyc.org/articulo. oa?id=15518482001. 